\title{
A 25 AÑOS DE SU CREACIÓN: COMENTARIOS A LA RELACIÓN ENTRE INDECOPI Y EL PODER JUDICIAL EN EL MARCO DE LOS PROCEDIMIENTOS CONCURSALES ${ }^{*}$ 25 YEARS OF ITS CREATION: COMMENTS ON THE RELATIONSHIP BETWEEN INDECOPI AND THE JUDICIAL POWER IN THE FRAMEWORK OF INSOLVENCY PROCEEDING
}

\author{
Renzo Agurto Isla** \\ Miranda \& Amado
}

\begin{abstract}
The insolvency system in Peru, besides having a private nature, has a sui generis administrative nature governed by the Insolvency Law, hence being supervised by the Indecopi. It is so that the later and the Judicial Power have a constant relationship that, if not properly regulated and developed, can cause negative consequences and disincentives on privats.
\end{abstract}

The author develops the aforementioned relationship through a historical account and, a development of the elements of its interaction. He focuses on the administrative litigation process and on its main basis, the right to effective judicial protection. On the other hand, it raises options of "temporary" solution to the determined challenges, due to the sui generis administrative nature of this system, to generate transparency and predictability in it.

KEY WORDS: Insolvency system; Indecopi; Judicial Power; administrative litigation process; due process law.
El sistema concursal en el Perú, además de tener una naturaleza privatista, tiene una naturaleza administrativa sui generis regida por la Ley Concursal, por lo que es supervisado por el Indecopi. Es así que este último y el Poder Judicial tienen una constante relación que, de no ser adecuadamente desarrollada, puede ocasionar consecuencias negativas y desincentivos en los privados.

El autor desarrolla la relación antes mencionada a través de un recuento histórico y un desarrollo de los elementos de su interacción. Se centra en el proceso contencioso-administrativo y en su principal fundamento, el derecho a la tutela jurisdiccional efectiva. Por otro lado, plantea opciones de solución "temporales" a los desafíos determinados, debido a la naturaleza administrativa sui generis de este sistema, para generar transparencia y predictibilidad en el mismo.

PalabRas Clave: Sistema concursal; Indecopi; Poder Judicial; proceso contencioso administrativo; tutela jurisdiccional efectiva.

* El autor agradece especialmente a Patricia Casaverde y Renzo Rossi, quienes forman parte del Área Concursal de Miranda \& Amado Abogados, por su colaboración y valioso aporte.

** Abogado. Magíster en Negocios, Derecho Corporativo y Marítimo por la Universidad Erasmus de Rotterdam, Holanda. Ex Consejero del Área Concursal del Estudio Rebaza, Alcázar \& De las Casas. Ex Asociado del Área de Banca, Finanzas y Restructuración de Empresas del Estudio Benites, Forno \& Ugaz. Consejero del Área Concursal del Estudio Mirada \& Amado. Contacto: ragurto@mafirma.com.pe.

Nota del Editor: El presente artículo fue recibido por el Consejo Editorial de THËMIS-Revista de Derecho el 15 de noviembre de 2017, y aceptado por el mismo el 21 de febrero de 2018. 


\section{UN POCO DE HISTORIA DEL DERECHO CONCURSAL}

La doctrina es pacífica en reconocer que el instituto de la quiebra, como ejecución colectiva, se originó en el Derecho Romano. Inicialmente se trataba de una ejecución contra y sobre la persona misma (instituciones denominadas manus iniectio y pignoris capio), para luego transformarse, de a pocos, en una ejecución sobre el patrimonio del deudor. Aunque con trascendentales diferencias, algunos conceptos que se empezaron a forjar en aquella época han sido una pieza fundamental para el desarrollo posterior del Derecho Concursal. Por ejemplo, en el medioevo se desarrollaron dos corrientes contrapuestas sobre la ejecución colectiva: (i) la primera que, siguiendo los principios del derecho romano, concibió al proceso de la "quiebra" con un cariz estrictamente privatista, bajo el cual la autoridad pública se limitaba a asistir a los acreedores del deudor para hacer efectivo sus derechos; (ii) mientras que la segunda, representada por el derecho visigodo, en una opinión contraria y con un fuerte carácter publicístico, estableció la continua injerencia de la autoridad judicial. Osvaldo (1992, pp. 141-150).

En el Perú, el Derecho Concursal ha sufrido marcados cambios a lo largo de su historia. La "historia oficial" comenzó en el año 1932, cuando se promulgó la Ley 7556, denominada Ley Procesal de Quiebras (Del Águila, 2003, p. 64). Esta Ley, que se mantuvo vigente hasta 1992, sostenía un modelo concursal judicial tradicional que se orientaba a realizar los activos del deudor para pagar sus obligaciones. El Poder Judicial, actor principal durante la vigencia de este modelo concursal, era el encargado de guiar, supervisar y conducir el proceso. Bajo este modelo, la intervención de los acreedores pasaba a un segundo plano, en tanto se entendía que la autoridad judicial velaba por todos ellos.

En el año 1992, el modelo cambió radicalmente. Se derogó la Ley Procesal de Quiebras y se promulgó el Decreto Ley No. 26116, Ley de Reestructuración Empresarial. A través de la mencionada norma se decidió "privatizar" y "desjudicializar" los procedimientos concursales. Para ello se creó una autoridad administrativa autónoma, especializada y con los recursos suficientes para tramitar los procedimientos concursales; además se le otorgó a la Junta de Acreedores la capacidad de decisión sobre el destino del deudor, entre otros. Así nació el Instituto Nacional de Defensa de la Competencia y de la Protección de la Propiedad Intelectual [en adelante, Indecopi] y, en específico, la Comisión de Procedimientos Concursales (primera instancia) y el Tribunal de la Sala Especializada en Procedimientos Concursales (segunda instancia) ${ }^{1}$, autoridad administrativa encargada de supervisar los procedimientos concursales a partir de ese entonces.

Este sistema "privatista" y "desjudicializado" constituyó, en ese entonces, una fórmula novedosa y, hasta donde conocemos, sin precedentes a nivel mundial. Como se mencionó en un artículo sobre la materia, nuestro régimen concursal es un auténtico "producto nacional" (Echeandía, 2001, p. 195). Desde entonces, si bien el modelo se ha mantenido, la regulación sobre la materia se ha modificado en varias ocasiones con base, principalmente, en la experiencia adquirida por la autoridad concursal y con la "intención" de dotar de celeridad y eficiencia al sistema concursal.

\section{LA REALIDAD DE NUESTRO SISTEMA CON- CURSAL EN LA ACTUALIDAD}

Actualmente el sistema concursal en nuestro país se rige por la Ley 27809, Ley General del Sistema Concursal, y sus modificatorias (en adelante Ley Concursal), así como por algunas otras normas para procedimientos de especial naturaleza. Hay consenso entre diversos autores en que la Ley Concursal es una norma con muchos aciertos que la hacen atractiva y ventajosa frente a esquemas vigentes en otros países (Ezcurra, 2002, p. 157) y que, en efecto, ha aportado beneficios a nuestro ordenamiento. A casi 25 años de su creación, este sistema sui generis se ha afianzado en nuestro país. Sin perjuicio de ello, tal como fue advertido en su momento por otros autores, un sistema administrativo encargado de tramitar y supervisar los procedimientos concursales involucra también una serie de desafíos que, de no ser bien abordados, pueden socavar las bases sobre las que dichos procedimientos están construidos (Indecopi, 2013, pp. 44 - 45).

Algunos de estos desafíos, abordados de forma incorrecta, han generado desincentivos en los distintos agentes de mercado que hacen uso del sistema concursal, al elevar los costos de transacción de los procedimientos concursales. Esto, a su vez, termina alejando al propio sistema de su objetivo primordial" . Como ejemplo de ello, "las acciones

Por razones de edición, únicamente hacemos referencia a los nombres actuales de las autoridades en materia concursal.

2 Artículo I - Título Preliminar de la Ley Concursal

El objetivo de la presente Ley es la recuperación del crédito mediante la regulación de procedimientos concursales que promuevan la asignación eficiente de recursos a fin de conseguir el máximo valor posible del patrimonio del deudor. 
de amparo y medidas cautelares se utilizan a diestra y siniestra como el mecanismo más eficaz para dejar sin efectos los acuerdos de los acreedores" (Ezcurra, 2016, p. 166).

En este trabajo nos enfocaremos en la naturaleza administrativa del sistema concursal y la relación entre la autoridad administrativa concursal y el Poder Judicial. Así pues, trataremos de abordar las siguientes preguntas: ¿Puede un sistema concursal "privatista" como el nuestro conjugar con el marco regular del sistema administrativo? ¿Un sistema "desjudicializado" como el nuestro debe tener un tratamiento administrativo regular? ¿A qué tipo de relación entre Indecopi y el Poder Judicial podemos aspirar? ¿En el estado de las cosas, el sistema concursal está cumpliendo su objetivo primordial?

\section{LA RELACIÓN ENTRE INDECOPI Y EL PODER JUDICIAL}

La relación entre ambas entidades, por la naturaleza y estructura propias del sistema concursal, es inevitable y se puede dar a lo largo de todas las etapas del concurso. Indecopi es la autoridad a cargo de la tramitación de los procedimientos concursales -que son procedimientos administrativos trilaterales-, y tiene competencia para conocer cualquier asunto vinculado a los mismos hasta la declaración judicial de quiebra del deudor o hasta que concluya el procedimiento concursal.

Sin embargo, precisamente al ser Indecopi una entidad administrativa, su actuación se desarroIla únicamente dentro de las facultades expresamente otorgadas. Se encuentra entonces limitada para emplear la fuerza para el cumplimiento de las medidas que ordene (coertio), para emitir una decisión definitiva que ponga fin al conflicto (iudicium) y para hacer uso de la fuerza pública para ejecuciones forzadas con base a sus resoluciones (executio), todo lo cual es propio de la función jurisdiccional del Poder Judicial. Asimismo, en el ejercicio de sus funciones, Indecopi debe observar el carácter vinculante de las decisiones judiciales, sin poder calificar sus fundamentos, restringir sus efectos o interpretar sus alcances bajo responsabilidad $^{3}$, ni avocarse a causas pendientes ante el Poder Judicial ${ }^{4}$.

Entonces, si bien Indecopi es la autoridad especializada en procedimientos concursales, con competencia exclusiva en sede administrativa para pronunciarse sobre los mismos; el Poder Judicial también interviene en los procedimientos concursales en la revisión de las impugnaciones a los actos administrativos emitidos por Indecopi. Así pues, el Poder Judicial se pronuncia sobre acciones de garantía u otorga medidas cautelares; determina y modifica situaciones de hecho respecto de los administrados al definir la existencia de créditos frente al deudor concursado; declara la ineficacia de los actos realizados dentro del periodo de sospecha; declara la quiebra del deudor concursado cuando corresponde; entre otros. Podemos ver entonces que la interacción y colaboración entre Indecopi y el Poder Judicial en los procedimientos concursales resulta determinante para el adecuado funcionamiento del sistema.

Para graficar con mayor detalle la interacción entre Indecopi y el Poder Judicial, a continuación, haremos mención a provisiones específicas de la Ley Concursal, así como a criterios que se han desarrollado en la práctica concursal que dan cuenta de la relación entre ambas entidades.

\section{A. Acciones de garantía y medidas cautelares}

La implementación de un sistema concursal de naturaleza administrativa ha generado reacciones diversas y encontradas, principalmente debido a que:

Esta virtud resultó siendo el punto más vulnerable del nuevo ordenamiento concursal, pues en innumerables oportunidades las decisio-

$3 \quad$ Artículo 4.- Texto Único Ordenado de la Ley Orgánica del Poder Judicial

Toda persona y autoridad está obligada a acatar y dar cumplimiento a las decisiones judiciales o de índole administrativa, emanadas de autoridad judicial competente, en sus propios términos, sin poder calificar su contenido o sus fundamentos, restringir sus efectos o interpretar sus alcances, bajo la responsabilidad civil, penal o administrativa que la ley señala. Ninguna autoridad, cualquiera sea su rango o denominación, fuera de la organización jerárquica del Poder Judicial, puede avocarse al conocimiento de causas pendientes ante el órgano jurisdiccional. No se puede dejar sin efecto resoluciones judiciales con autoridad de cosa juzgada, ni modificar su contenido, ni retardar su ejecución, ni cortar procedimientos en trámite, bajo la responsabilidad política, administrativa, civil y penal que la ley determine en cada caso. Esta disposición no afecta el derecho de gracia.

4 Artículo 139.- Constitución Política del Perú

Son principios y derechos de la función jurisdiccional:

1. La unidad y exclusividad de la función jurisdiccional. No existe ni puede establecerse jurisdicción alguna independiente, con excepción de la militar y la arbitral. No hay proceso judicial por comisión o delegación.

2. La independencia en el ejercicio de la función jurisdiccional. Ninguna autoridad puede avocarse a causas pendientes ante el órgano jurisdiccional ni interferir en el ejercicio de sus funciones. Tampoco puede dejar sin efecto resoluciones que han pasado en autoridad de cosa juzgada, ni cortar procedimientos en trámite, ni modificar sentencias ni retardar su ejecución. (...) 
nes que se adoptaron en sede administrativa resultaron neutralizadas a través de pronunciamientos jurisdiccionales, no solo en la vía contencioso-administrativa, sino incluso a través de acciones de amparo y procesos civiles (Espinoza y Atoche, 2011, p. 904).

Consideramos que las acciones de garantía y medidas cautelares emitidas por el Poder Judicial en el marco de los procedimientos concursales que se han llevado a cabo durante todos estos años han sido un elemento que ha puesto en tela de juicio la eficiencia del sistema concursal, especialmente por el efecto dilatorio y la falta de predictibilidad que ello ha generado en los procedimientos concursales.

Podemos notar como ya en el año 2002, en un proyecto de ley previo a la promulgación de la Ley Concursal, el legislador enfatizó la importancia de regular la relación de los procedimientos concursales con la actividad que el Poder Judicial puede tener frente a ellos. Esto, debido a la experiencia en "casos de procedimientos concursales en marcha con decisiones adoptadas y expeditas para ser ejecutadas, que eran interferidos por decisiones judiciales en vista del uso, muchas veces abusivo, de las garantías constitucionales u otras demandas en sede judicial."

Esta situación se mantuvo en el tiempo en los procedimientos concursales tramitados por Indecopi; ya que, recién en el año 2005, la Corte Suprema de Justicia se pronunció al respecto mediante el Oficio Circular 007-2005-SP-CS-PJ en diciembre de 2005 de la forma siguiente:

ACUERDO: Primero.- La intervención de los órganos jurisdiccionales se debe producir en las formas taxativamente señaladas en la Ley General del Sistema Concursal (...); esto es, con la finalidad de evitar dilaciones innecesarias. Se exhorta a los presidentes de las Cortes Superiores de Justicia de la República, a tomar las medidas del caso para el cabal cumplimiento de las recomendaciones antes mencionadas.

Esta invocación a observar la Ley Concursal fue compartida por el Tribunal de Indecopi que señaló que las reglas procesales especiales para las instancias judiciales a cargo del control de la legalidad de las decisiones de dicha institución, así como las vías procesales apropiadas para el desarrollo de la función jurisdiccional en esta materia -establecidos en los artículos 132 y 133 de la Ley Concursal-:, "constituyen un mecanismo para canalizar pretensiones de los justiciables que consideren que sus derechos han sido lesionados al interior de un procedimiento concursal". Por ello, atendiendo a las experiencias ocurridas en los procedimientos concursales, "recae en los particulares y especialmente en los jueces la responsabilidad de utilizar estos mecanismos procesales con arreglo a lo dispuesto en la ley." ${ }^{\prime 6}$

Actualmente, la Ley Concursal establece que las resoluciones que agoten la vía administrativa en los procedimientos concursales sólo pueden ser impugnadas en la vía del proceso contenciosoadministrativo $^{7}$. Además, las solicitudes de medidas cautelares para suspender o producir efectos análogos en los procedimientos concursales sólo se podrán resolver con ocasión del proceso contencioso-administrativo ${ }^{8}$.

Asimismo, las acciones de garantía sólo proceden cuando se agota la vía administrativa previa, salvo las excepciones previstas en la Ley de Hábeas

5 Para mayor información revisar: Exposición de motivos del Proyecto de Ley 2579-2001-CR, que deroga la ley de Reestructuración Patrimonial, el Procedimiento Simplificado y el Concurso Preventivo (para dar paso a la Ley Concursal). Disponible en: http://www2.congreso.gob.pe/Sicr/TraDocEstPorc/TraDoc_condoc_2001.nsf/d99575da99ebfbe305256f2e006d1cf0/bd03ba1735bc450e05257592004f882c/\$FILE/02579.pdf

6 Resolución 949-2006/TDC-INDECOPI contenida en el expediente 88-2004/CCO-ODI-ESN-03-09, en el procedimiento concursal de Red Global S.A., reconocimiento de créditos de Astros S.A.

7 Artículo 132.- Ley Concursal

Órganos de competencia exclusiva.

132.1 Tienen competencia exclusiva para resolver las impugnaciones de las resoluciones que se emitan en cualquier procedimiento concursal en materias reguladas por esta Ley, las Comisiones de Procedimientos Concursales y el Tribunal del Indecopi, en sede administrativa, y las Salas correspondientes, en sede judicial.

132.2 Las resoluciones que agoten la vía administrativa en los procedimientos concursales, sólo pueden ser impugnadas en la vía del proceso contencioso administrativo. Por consiguiente, no procede el uso de vías procesales distintas para impugnar acuerdos, decisiones o resoluciones en asuntos derivados de la aplicación de la Ley y sus normas complementarias, ni para suspender, invalidar o inaplicar sus efectos.

$8 \quad$ Artículo 133.- Ley Concursal

Instancias competentes en acciones de garantía u otras demandas judiciales en materia concursal.

133.1 Las acciones de garantía sólo proceden cuando se agota la vía administrativa previa, salvo las excepciones previstas en la Ley de Hábeas Corpus y Amparo y serán conocidas en primera instancia por la Sala Superior Especializada en lo Civil de la Corte Superior de Justicia y en grado de apelación por la Sala Constitucional y Social de la Corte Suprema de Justicia de la República. 
Corpus y Amparo, y serán conocidas en primera instancia por la Sala Superior Especializada en lo Civil de la Corte Superior de Justicia y en grado de apelación por la Sala Constitucional y Social de la Corte Suprema de Justicia de la República. La Ley Concursal establece que, de no respetarse las vías procesales indicadas, Indecopi pondrá ello en conocimiento del Consejo Nacional de la Magistratura y la Oficina de Control de la Magistratura a fin de responsabilizar al órgano jurisdiccional por su actuación, a través de un proceso disciplinario. ${ }^{9}$

En este punto, consideramos pertinente resaltar que las provisiones de la Ley Concursal mencionadas están referidas a cuestionamientos respecto de actos administrativos que emita el Indecopi (que pueden referirse a inicios de concurso, reconocimientos de crédito, impugnaciones de acuerdos de juntas de acreedores, entre otros) y que, además, existirán circunstancias en las que lo indicado en los párrafos anteriores no resultará de aplicación. Ejemplo de esto último son aquellos casos en los que se busca evitar ejecuciones de bienes de propiedad de terceros o de bienes otorgados en garantía de terceros ajenos al procedimiento concursal.

\section{B. Suspensión del procedimiento de recono- cimiento de créditos y registro de créditos contingentes}

La actuación de Indecopi en la etapa de reconocimiento de créditos reviste especial importancia dado que tiene como consecuencia la definición de qué créditos se incorporarán al concurso y en qué medida sus titulares participarán en el órgano (la Junta de Acreedores) que decidirá principalmente el destino del deudor y la aprobación del negocio jurídico que hace viable dicho destino (Plan de Restructuración, Acuerdo Global de Refinanciación de Obligaciones o Convenio de Liquidación). En tal sentido, se deberá procurar, a través de la evaluación de Indecopi, que la masa concursal responda efectivamente a la realidad de los créditos comprometidos en el concurso.

Por ello, Indecopi investigará la existencia, origen, legitimidad y cuantía de los créditos invocados por los acreedores a fin de emitir un pronunciamiento sobre la procedencia de las solicitudes. Sin embargo, existen ciertas particularidades en el trámite del reconocimiento de créditos que reflejan la interacción entre Indecopi y el Poder Judicial, como es el caso del registro como contingentes de aquellos créditos respecto de los que existe una controversia sobre su existencia, origen, legitimidad y cuantía, así como la consecuente suspensión del trámite del reconocimiento de tales créditos hasta que la controversia sea definida.

Al respecto, la Ley Concursal establece en su artículo 39.5 que son créditos contingentes aquellos controvertidos judicial, arbitral o administrativamente; los mismos que serán registrados por la Comisión de Procedimientos Concursales como tales, siempre que la controversia esté referida a su existencia, origen, legitimidad, cuantía o titularidad, y el asunto controvertido sólo pueda dilucidarse en el fuero judicial, arbitral o administrativo, por ser competencia exclusiva de la autoridad a cargo. Indecopi sólo podrá suspender el reconocimiento de créditos por mandato expreso del Poder Judicial, Árbitro o Tribunal Arbitral que ordene la suspensión, o en caso de que exista una sentencia o laudo arbitral que señale la nulidad o ineficacia de la obligación.

Lo anterior, según criterio desarrollado por Indecopi en diversas resoluciones ${ }^{10}$, debe ser interpretado conjuntamente con el artículo 65 del Decreto legislativo 807, Facultades, normas y organización del Indecopi. Dicho Decreto establece que los órganos funcionales de Indecopi suspenderán la tramitación de los procedimientos que ante ellos se

133.2 Las solicitudes de medidas cautelares que tengan por objeto suspender o producir cualquier efecto análogo en los procedimientos regulado en la Ley, sólo podrán ser tramitadas y resueltas con ocasión del proceso contencioso administrativo que se promovió con arreglo a ley.

133.3 En los casos de las resoluciones judiciales referidas a acciones de garantía o medidas cautelares en materia concursal que no hayan sido expedidas por los órganos jurisdiccionales señalados en el numeral 133.1 precedente, o que hayan sido tramitadas en vías procesales distintas a la indicada en el numeral 133.2 precedente, el INDECOPI deberá poner lo actuado en conocimiento del Consejo Nacional de la Magistratura, así como de la Oficina de Control de la Magistratura respectiva para que de oficio inicie el proceso disciplinario correspondiente.

133.4 Las demandas judiciales que se promuevan con relación a procedimientos regulados por la Ley, deberán efectuarse con citación al Indecopi.

$9 \quad$ Adicionalmente, la Ley Concursal establece ciertos efectos para quien interponga acciones judiciales en materia concursal que suspendan el procedimiento, tales como el levantamiento de la suspensión de la exigibilidad de obligaciones y el levantamiento de las medidas de protección patrimonial para aquellos deudores que solicitaron el inicio de su concurso. Ello, bajo el criterio de que si el deudor no respeta las reglas del procedimiento que él mismo inicio cuando estas ya no le resultan favorables, no se puede exigir tampoco que sus acreedores se mantengan atados a las reglas de orden del procedimiento concursal.

10 Revisar, por ejemplo, la Resolución 81-2010/SC1-INDECOPI en el procedimiento concursal de Flor Marleny Tarrillo Fernández Viuda de la Cruz, en el reconocimiento de créditos seguido por Banco de Crédito del Perú. 
siguen sólo en caso de que, con anterioridad al inicio del procedimiento administrativo, se haya iniciado un proceso judicial que verse sobre la misma materia o cuando surja una cuestión contenciosa que, a criterio del Tribunal, Comisión u Oficina respectiva, precise de un pronunciamiento previo sin el cual no puede ser resuelto el asunto que se tramita ante Indecopi.

Debe considerarse que, en la práctica, el suspender el reconocimiento de determinado crédito y registrarlo como contingente podría comportar graves consecuencias para un acreedor ya que incide en su participación efectiva (voz y voto) en las sesiones de Junta de Acreedores. Por tal motivo, la evaluación de la contingencia considera varios elementos como el que el proceso judicial se haya iniciado con anterioridad a la situación de concurso, que el proceso efectivamente esté dirigido a una declaración de derechos y que en él se discuta la existencia, origen, legitimidad, cuantía o titularidad de los créditos. Por ello, en el caso de procesos ejecutivos respecto de los créditos cuyo reconocimiento se solicita, no procedería, en principio, suspender su reconocimiento ni registrarlos como contingentes.

\section{Nulidad de Cosa Juzgada Fraudulenta}

Tanto en el caso de solicitudes de inicio de procedimientos concursales a pedido de acreedor como en el reconocimiento de créditos, la Ley Concursal señala que aquellos créditos que sustenten el pedido y que tengan como soporte sentencias judiciales consentidas o ejecutoriadas o laudos arbitrales, serán reconocidos por el solo mérito de su presentación.

De otro lado, el artículo 135 de la Ley Concursal otorga facultades al Indecopi para interponer una demanda de nulidad de cosa juzgada con efecto concursal. Este mecanismo responde a la experiencia práctica en la implementación del sistema concursal que ha permitido a Indecopi advertir la existencia de créditos simulados que generan distorsiones en la composición de la Junta de Acreedores $y$, finalmente, en el resultado del concurso. En la medida que Indecopi fue desarrollando investigaciones más detalladas y exhaustivas -con precedentes de observancia obligatoria de por medio ${ }^{11}$ y haciendo uso de las facultades de investigación que la ley le otorga- a fin de cumplir con su rol de verificación de la existencia de créditos, también los particulares fueron afinando algunas técnicas para simular la existencia de créditos, incluyendo en algún caso el uso de sentencias firmes.

El artículo 135 de la Ley Concursal dispone que Indecopi cuenta con facultades para disponer que se inicie un proceso judicial de nulidad de sentencia judicial o laudo arbitral, transacción judicial o extrajudicial, o de cualquier acto o convenio que por ley tenga autoridad de cosa juzgada. Ello, cuando considere que existen elementos de juicio suficientes que generen dudas acerca de la existencia y origen de los créditos que hayan sido presentados como acto privado o por orden judicial para sustentar el inicio de un procedimiento concursal o como sustento de la solicitud de reconocimiento de créditos al interior de un procedimiento concursal ya iniciado ${ }^{12}$.

Esta disposición existe desde el año 2002 en la Ley Concursal; sin embargo, fue modificada no hace mucho, buscando ajustar la denominación "cosa juzgada fraudulenta con efecto concursal" para resaltar el carácter especial de una acción en la que Indecopi, que no participó en el proceso que resultó en un acto con calidad de cosa juzgada, se encuentre legitimado a cuestionar los resultados del mismo. La modificación extendió también los actos respecto de los cuales Indecopi podrá demandar la

11 Precedente de Observancia Obligatoria contenido en la Resolución No. 079-97-TDC.

12 Artículo 135. - Ley Concursal

Facultades de la Comisión para interponer demanda de nulidad de cosa juzgada con efecto concursal.

135.1 La Comisión ante la cual se tramita un procedimiento concursal cuenta con facultades para disponer se inicie un proceso judicial de nulidad de sentencia judicial o arbitral, transacción judicial o extrajudicial o de cualquier acto o convenio que por Ley tenga autoridad de cosa juzgada. La Comisión solicitará la interposición de la demanda a la que se refiere el párrafo anterior, cuando considere que existen elementos de juicio suficientes que generen dudas acerca de la existencia y origen de los créditos creados, modificados, extinguidos o reconocidos en estos actos y que hayan sido presentados como acto privado o por orden judicial, para sustentar el inicio de un procedimiento concursal o como sustento de la solicitud de reconocimiento de créditos al interior de un procedimiento concursal ya iniciado. La decisión de iniciar el proceso judicial es impugnable con efecto suspensivo. El proceso se tramita en la vía del proceso abreviado. El plazo para interponer la demanda prescribe a los veinticuatro meses de presentada la sentencia, convenio u otro acto con valor de cosa juzgada ante la Comisión, conforme a lo señalado en los párrafos precedentes.

135.2 Con la sola presentación de la demanda se suspenderá de pleno derecho el procedimiento concursal iniciado por el mérito de la sentencia, convenio o acto mencionados en el numeral 135.1 artículo 135, así como el procedimiento de reconocimiento de créditos que se sustenta en los indicados documentos y que son materia de cuestionamiento, mientras dure el proceso judicial correspondiente y se emita resolución definitiva. En dichos supuestos, la Comisión procederá a registrar como contingentes a los créditos objeto de la demanda de nulidad de cosa juzgada con efecto concursal, conforme a lo establecido en el numeral 39.5 del Artículo 39. 
nulidad de cosa juzgada con efecto concursal, incluyendo, además de sentencias judiciales, laudos arbitrales, transacciones y cualquier acto o convenio con calidad de cosa juzgada. Precisó que ello resultará de aplicación tanto en los supuestos en los que se solicite un reconocimiento de créditos como en las solicitudes de inicio de procedimiento concursal. Además, estableció que el proceso se tramitará en la vía abreviada y que el plazo para interponer la demanda prescribe a los veinticuatro meses de presentado el acto con calidad de cosa juzgada.

\section{LA IMPUGNACIÓN DE LOS ACTOS ADMINIS- TRATIVOS}

Como hemos detallado en la sección III de este artículo, la relación Indecopi y el Poder Judicial es una necesidad propia de la naturaleza y estructura del procedimiento concursal. La relación entre estas dos entidades puede darse de formas diversas $y$, en esta sección, vamos a desarrollar de manera específica una de ellas que, por cierto, consideramos de trascendental relevancia por su impacto en los procedimientos concursales: la impugnación de los actos administrativos a través del proceso contencioso-administrativo.

Para desarrollar este asunto no podemos perder de vista la naturaleza propia de nuestro sistema concursal. Como hicimos mención en la sección I, nuestro sistema es: (i) de carácter privatista, en la medida que se les da a los acreedores una enorme (si no toda) capacidad de decisión sobre diversos aspectos que atañen al deudor, entre ellos, su destino; y, (ii) administrativo, en la medida que la autoridad encargada de conducirlo es el Indecopi, una entidad autónoma de carácter administrativo. El Poder Judicial solo tiene un rol complementario (pero, como se evidencia en la sección III anterior, no por eso, menos importante).

En efecto son los acreedores quienes toman las decisiones al interior de un procedimiento concursal. Si bien el Indecopi decide si el deudor debe quedar o no sometido a concurso, una vez que la Junta de Acreedores queda instalada, esta se encarga de decidir lo más conveniente en función de sus intereses. Indecopi solo se encarga de supervisar el cumplimiento de las formalidades y la legalidad de los acuerdos adoptados por la Junta de Acreedores.

\section{A. El proceso contencioso administrativo en el Perú}

El diseño del proceso contencioso-administrativo en el Perú puede remontarse a la Constitución de 1867, en cuyo artículo 130 se establecía que la ley determinará la organización de los Tribunales contenciosos-administrativos, y lo relativo al nombramiento de sus miembros. Sin embargo, hubo que esperar varios años para que esto se consagrase, al menos a nivel legislativo. Así, fue recién la Ley Orgánica del Poder Judicial de 1963 la que, en su artículo 12 , consagró con carácter general, la posibilidad de cuestionar ante el Poder Judicial los actos de la Administración Pública (Danós en Priori, 2009, p. 53).

Luego de ello, se dieron algunas modificaciones a nivel legislativo hasta que la Constitución de 1993 (precedida por la del año 1979) estableció que "las resoluciones administrativas que causan estado son susceptibles de impugnación mediante la acción contencioso-administrativa". Esto dio pie a que el 7 de diciembre de 2001 (luego un trabajo prolijo de la Comisión del Congreso encargada de su formulación) fuese publicada en el Diario Oficial El Peruano, la Ley del Proceso Contencioso-Administrativo, Ley 27584. Con modificaciones de por medio, que incluso generaron la elaboración de un Texto Único Ordenado. Podemos decir que la justicia contencioso-administrativa como la conocemos hoy nació en el Perú en ese entonces (Priori, 2009, p. 56).

Al respecto, la doctrina es uniforme al considerar que el proceso contencioso-administrativo se basa en los siguientes fundamentos (Priori, 2009, p. 57; Ledesma, 2009, pp. 165-168):

- El Estado constitucional y el principio de constitucionalidad.

Los derechos fundamentales.

La necesidad de control entre los diversos órganos del Estado.

- $\quad$ El derecho a la tutela jurisdiccional efectiva.

En las líneas siguientes, a efectos de desarrollar la relación entre Indecopi y el Poder Judicial, nos centraremos en el tercer y cuarto fundamento del proceso contencioso-administrativo.

1. La necesidad de control entre los diversos órganos del Estado

El reconocimiento por parte del Estado de los derechos que corresponde a cada uno de sus ciudadanos, acarrea como inmediata consecuencia que se pueda controlar el poder que ejerce el propio Estado. Estos controles pueden ser intraorgánicos e interorgánicos. Dentro de la administración pública, las propias entidades administrativas están obligadas a contar con un órgano de control intraórganico; mientras que el 
proceso contencioso-administrativo se presenta como una herramienta que permite el control interorgánico por parte del Poder Judicial hacia la administración a fin de garantizar el respeto del principio de constitucionalidad.

\section{El derecho a la tutela jurisdiccional efectiva}

El derecho a la tutela jurisdiccional efectiva, por su parte, es uno de los principales fundamentos sobre los que descansa el proceso contencioso-administrativo. Esto es, "el derecho de toda persona a que se haga justicia; a que cuando pretenda algo de otra, esta pretensión sea atendida por un órgano jurisdiccional, a través de un proceso con unas garantías mínimas" (Gonzáles, 2001, p. 33) y que esta sentencia sea finalmente ejecutada.

Ahora, si bien el derecho constitucional a la tutela jurisdiccional efectiva es un derecho exigible en cualquier proceso, las razones por las cuales el derecho a la tutela jurisdiccional efectiva es un fundamento (a nuestro criterio el más importante) del proceso contencioso-administrativo, difieren sustancialmente de aquellas que se debería brindar para el proceso civil.

Como ha detallado Priori, desde una perspectiva civil, la autotutela de derechos está prohibida, por lo que la tutela jurisdiccional efectiva, como una herramienta hetero compositiva de resolución de conflictos, resulta de trascendental importancia. Surgido un conflicto de intereses en el que los sujetos no se puedan poner de acuerdo por cuenta propia, estos no tienen otra opción más que acudir al órgano jurisdiccional para resolver sus conflictos. El derecho a la tutela jurisdiccional efectiva se convierte en la única forma de garantizar a los ciudadanos una efectiva protección de sus situaciones jurídicas subjetivas (Priori, 2009, p. 81).

Sin embargo, el fundamento de la tutela jurisdiccional efectiva durante el proceso civil no puede asemejarse al proceso contencioso-administrativo, pues este último, como afirma Gonzáles:

Tiene como presupuesto una situación de conflicto en la cual una de las partes tiene autorizado el recurso de autotutela. En efecto, la Administración Pública y las entidades que la integran, están investidas de unas prerrogativas excepcionales que las dispensan de acudir a los jueces para dirimir los conflictos jurídicos y para realizar forzosamente sus decisiones frente a los obligados $(1985$, p. 3).

En otras palabras, la Administración Pública se encontraría en una situación privilegiada, debido a que:
(...) siendo ella parte del conflicto de intereses que tiene frente a un particular [aunque no en todos los casos, como sostendremos más adelante], sea ella misma la que resuelva dicho conflicto a través de un procedimiento administrativo, al término del cual dictará un acto administrativo que tendrá como una de sus principales características la ejecutoriedad (Priori, 2009, p. 83).

Es decir, deberá ejecutarse dicho acto administrativo sin que hubiese sido necesario acudir a un órgano jurisdiccional.

Es evidente que dicha situación que se explica en función de los intereses generales que está llamada a cumplir la Administración, podría dar lugar a arbitrariedades; pues el ejercicio de dicha función puede no ser ejercida con arreglo a la Constitución y a la ley (es decir, burlando el principio de constitucionalidad), lo que puede suponer la vulneración de derechos e intereses legítimos de los particulares (Priori, 2009, p. 83).

En suma, queremos poner énfasis en que el legislador, al establecer el proceso contencioso-administrativo, ha considerado de suma relevancia el conflicto de interés que es natural en una relación del administrado con la propia Administración. Este natural conflicto de interés ha servido como uno de los fundamentos para que, bajo el derecho a una tutela jurisdiccional efectiva, se idealice y se estructure el proceso contencioso-administrativo, a través del cual un tercero imparcial (como es el Poder Judicial) se encontraría en una posición más objetiva para resolver el conflicto suscitado.

\section{B. El Sistema Concursal Peruano es sui generis}

Regresemos pues a los fundamentos de nuestro sistema concursal. Como recordarán, el sistema concursal peruano es uno de naturaleza administrativa. Por lo que, en este caso el legislador y los diversos agentes del mercado han entendido, sin cuestionar mucho su aplicación, que el derecho a la tutela jurisdiccional efectiva debe aplicarse sin miramientos. Sin embargo, esto podría ser una de sus principales debilidades. Si las decisiones de la autoridad administrativa son cuestionadas en el Poder Judicial de forma regular, esto sin duda alguna implica una demora y/o un cambio de decisión respecto de las decisiones adoptadas por Indecopi, con todas las consecuencias negativas que aquello genera en los acreedores y en todos los agentes de mercado, quienes esperan un mecanismo que ayude a resolver la insolvencia del deudor de una forma rápida y eficiente, y no que se mantenga en trámite durante años en el Poder Judicial. 
No pretendemos desconocer el derecho a la tutela jurisdiccional, que como ya hemos detallado, es un derecho constitucionalmente reconocido e interiorizado en nuestro sistema; pero creemos importante cuestionar su aplicación (sin distinciones) en diversas estructuras administrativas que tienen matices y formulaciones diversas.

El Perú mantiene desde el año 1992 un sistema concursal sui generis. No es común que sea una autoridad administrativa la encargada de tramitar y supervisar los procedimientos concursales. Pero su carácter administrativo va íntimamente conectado con su carácter privatista. Darles a los acreedores el poder suficiente durante el procedimiento concursal permite que la Administración Pública no sea la encargada de disponer sobre los derechos de los administrados, sino que sean estos mismos quienes acuerden la mejor solución para un problema que nació de esa misma forma, entre privados.

En el Perú, hemos ido de más a menos Estado en los procedimientos concursales. Parte central de los procedimientos concursales es la decisión de negocio relativa al destino del deudor (reestructuración o liquidación), así como todas aquellas decisiones relacionadas a ello (valuación de negocio en marcha y negocio en liquidación, decisión sobre plazo y formas de pago, régimen de administración, entre otros). Todas esas han sido delegadas a los principales interesados en el procedimiento concursal: los propios acreedores. Lo anterior tiene un fundamento; como detalla Huáscar Ezcurra:

El Estado no tiene los incentivos adecuados para tomar decisiones de negocio correctas, pues no gana por una decisión correcta. Como el Estado no se ve afectado por las decisiones que tome, hay el riesgo de que tome la decisión incorrecta. Los privados (acreedores), en cambio, sí tienen los incentivos adecuados para tomar decisiones correctas. Los acreedores perderán si se equivocan al tomar su decisión, pues recuperarán una menor parte de sus créditos. Y ganarán si toman la decisión correcta, pues incrementarán sus posibilidades de recupero. En ese sentido, los privados tienen los incentivos adecuados para informarse sobre la realidad del negocio, valuarlo adecuadamente y, optar, en función de ello, por la reestructuración o la liquidación, según cuál opción les dé mayor valor. Asimismo, tienen los mejores incentivos para designar a la administración que les dé mayores garantías de generar valor, y establecer la forma de pagos más conveniente a sus intereses, etc. (2002, p. 50).

Ahora bien, si el Estado no tiene los incentivos adecuados para tomar las mejores decisiones so- bre un problema de carácter privado, y por, sobre todo, no tiene un conflicto de interés con el potencial administrado, pues en nada le beneficia o le perjudica, por ejemplo, el destino del deudor (sino que beneficia o perjudica única y exclusivamente a los acreedores o eventualmente al propio deudor), ¿realmente existen fundamentos para que el administrado pueda cuestionar las decisiones adoptadas por Indecopi ante el Poder Judicial?

Recordemos que uno de los principales fundamentos (sino el más importante) del proceso contencioso-administrativo es el derecho a una tutela jurisdiccional efectiva, y este a su vez, se basa esencialmente en el potencial conflicto de interés que tendría la Administración Pública con el administrado. Sin embargo, como se podrá inferir, Indecopi durante la tramitación de un procedimiento concursal no tiene un conflicto de interés con el administrado. En esa línea, el derecho a la tutela jurisdiccional efectiva, uno de los principales fundamentos que sostienen la existencia de un proceso contencioso-administrativo durante la tramitación de los procedimientos concursales se ve, al menos, diluido.

Como hemos desarrollado a lo largo de este artículo, el procedimiento concursal es uno de carácter privatista. Por ejemplo, ante la falta de pagos generalizada por parte de un deudor, lo que podría afectar al mercado en general, la Administración Pública toma cartas en el asunto. Sin embargo, toma acción solo como un supervisor, una especie de tercero imparcial que se encuentra únicamente facultado para verificar el cumplimiento de los requisitos que impone la legislación para que un deudor sea sometido a concurso, para que un crédito sea reconocido, así como para que se encargue de velar por la legalidad de los acuerdos, entre otros.

Tomando en cuenta todo lo anterior, queda claro que un instituto como el proceso contencioso-administrativo debería ser analizado con detenimiento a la luz de la naturaleza de los procedimientos concursales en nuestro país. Uno de sus principales fundamentos, el derecho a una tutela jurisdiccional efectiva frente a un eventual conflicto de interés que podría desarrollar la Administración frente al administrado, parece no aplicarse durante la tramitación de un procedimiento concursal, en donde los principales interesados son los propios acreedores y no la Administración.

\section{La realidad de la justicia contencioso-admi- nistrativa en el Perú}

Reiteramos que el análisis presentado en la sección anterior no pretende desconocer el régimen 
legal vigente. Es la propia Constitución la que establece expresamente que son susceptibles de impugnación mediante la acción contenciosoadministrativa todas las resoluciones administrativas que causan estado. Ante este panorama, nuestro interés es graficar un problema que surge desde su concepción, para que los agentes del mercado (y en especial quienes se encargan de aplicar este régimen especial) puedan tomarlo en cuenta, profundizar sobre ello y eventualmente, por qué no, cuestionarlo.

Así, como se ha visto en la sección III de este artículo, conviene resaltar que este recurso contencioso-administrativo de no ser bien aplicado, puede traer innumerables consecuencias negativas, inclusive frente a quienes pretende proteger, que son los propios administrados, al ralentizar y torpedear decisiones emitidas por la autoridad administrativa especializada, en búsqueda de una tutela jurisdiccional efectiva.

\section{ALGUNAS PROPUESTAS DE SOLUCIÓN: PAR- TAMOS DE LOS OBJETIVOS FUNDAMENTA- LES Y LA ESTRUCTURA PARA UN RÉGIMEN CONCURSAL, EFICAZ Y EFICIENTE}

Por lo pronto, y mientras este tema no sea puesto en agenda, se mantendrá la estructura a la que nos hemos acostumbrado durante estos 25 años. En esa línea; sin embargo, creemos que podrían adoptarse algunas acciones que permitan mejorar la eficacia y eficiencia de nuestro sistema concursal y nos permitan hacer frente, al menos parcialmente, a una de sus principales debilidades: su naturaleza administrativa. Al final, como lo plantea la Comisión de las Naciones Unidas para el Derecho Mercantil Internacional, los objetivos fundamentales que debe perseguir un sistema concursal eficaz y eficiente, están relacionados a dar seguridad en el mercado para promover la estabilidad y el crecimiento económicos; lograr una solución oportuna, eficiente e imparcial de la situación de insolvencia; y garantizar un régimen de la insolvencia transparente y previsible que comprenda incentivos para reunir y facilitar la información (2006).

Así pues, por el momento, creemos que una primera propuesta de solución podría abarcar el acercamiento real entre Indecopi y el Poder Judicial a través de un convenio de colaboración que permita la capacitación y unificación de criterios de interpretación sobre nuestro sistema concursal. Al final, el Poder Judicial no es el enemigo de Indecopi. Por el contrario, ambos son actores principales en una obra que lo único que debe buscar es la dinamización y promoción del mercado para beneficio de todos sus agentes.

En esa línea, y como parte del Convenio Marco de Cooperación Interinstitucional entre el Poder Judicial de la República del Perú y el Instituto Nacional de Defensa de la Competencia y de la Protección de la Propiedad Intelectual, firmado el 31 de octubre de 2014, los titulares de ambas entidades del Estado podrían ponerse de acuerdo para suscribir un convenio de capacitación y/o de colaboración, a través de un intercambio de ideas y criterios, de tal forma que se busque alcanzar la unificación estructurada de criterios de interpretación de las normas que regulan el sistema concursal. Esto no sólo le otorgaría seguridad jurídica a los administrados, sino que podría reducir el número de procesos contencioso-administrativos si los potenciales impugnantes conocen que el criterio adoptado por Indecopi con dificultad variará al ser cuestionado frente al Poder Judicial.

Una segunda propuesta de solución, que ya adelantó algún autor nacional en su momento, puede ser la creación de juzgados especializados en procedimientos concursales. Lo que se podría conseguir con esta propuesta es que quienes se encarguen de resolver los procesos contenciosoadministrativos derivados de procedimientos concursales, tengan un profundo conocimiento de la legislación y jurisprudencia concursal. De esa forma, enfrentaríamos en estos procesos a autoridades judiciales mejor preparadas que puedan dar mejores soluciones.

Una tercera propuesta de solución, aprovechando un concepto de extensivo uso en el ámbito del derecho de la competencia, es que Indecopi ejerza una función de promoción y difusión de la cultura y los principios concursales teniendo como objetivo compartir experiencias, criterios e incluso recomendaciones con autoridades públicas así como con agentes privados sobre temas propios de un concurso. Esta sugerencia parte de haber identificado en nuestra práctica la necesidad de comunicar cómo y por qué los procedimientos concursales funcionan de una forma excepcional, así como los principios que rigen los mismos. Consideramos que ello constituiría un complemento relevante para los agentes del mercado, y una alternativa con vocación de difusión de conocimiento jurídico. Esto permitiría aprovechar la importante experiencia que Indecopi ha acumulado respecto del Derecho Concursal a lo largo de estos años ${ }^{13}$.

13 El Indecopi viene haciendo uso de la abogacía de la competencia en diversos ámbitos a fin de tener un rol más proactivo en la defensa, difusión y mejora de las materias de su competencia. 
Una cuarta propuesta de solución, que podría ir de la mano con nuestra primera propuesta (Convenio de Cooperación Interinstitucional), consiste en promover redes de especialización del Poder Judicial y de la Administración Pública. A nivel internacional, hemos identificado un proyecto que recientemente ha sido puesto en marcha, para la mejora del sistema concursal. Se trata del Judicial Insolvency Network, creado en 2016 a iniciativa de la Corte Suprema de Singapur y que a la fecha cuenta con miembros de Argentina y Brasil, entre otros países, que buscan promover la comunicación y la implementación de buenas prácticas en asuntos concursales dada la creciente complejidad de las crisis patrimoniales para el desarrollo de las empresas y el comercio internacional. Así, la mira final de esta red es compartir información y experiencias para casos de insolvencias transfronterizas ${ }^{14}$.

Estas son algunas propuestas que nos podrían permitir enfrentar, por ahora, el desafío que implica la naturaleza administrativa de nuestro sistema concursal, y en específico, reducir al menos parcialmente, el impacto que significa la interacción de Indecopi con el Poder Judicial en las distintas manifestaciones durante la tramitación de los procedimientos concursales.

Sin duda que estas no son las únicas soluciones posibles al problema que hemos graficado. Por lo pronto, nos basta con haber despertado en el lector algunas dudas, que le permitan profundizar, desarmar y quién sabe, después rearmar o inclusive, cuestionar nuestra propia tesis.

\section{CONCLUSIONES}

- No cuestionamos ni pretendemos proponer un cambio en el carácter administrativo del sistema concursal. A veinticinco años de su creación, este sistema privatista y con una autoridad administrativa que tramita y supervisa los procedimientos concursales, presenta más ventajas que uno de carácter judicial. Lo que sí creemos es que una propuesta sui generis como esta representa una serie de desafíos que deben ser adecuadamente administrados para que pueda lograr cumplir con su objetivo -la recuperación del crédito- de forma eficiente y eficaz.

- $\quad$ La interacción entre Indecopi y el Poder Judicial es diversa e intensa a lo largo de todas las etapas del concurso y resulta determinante para el adecuado funcionamiento del sistema. Una de las principales interacciones se da a través de la tramitación de los procesos contenciosos-administrativos.

- Durante la tramitación de un procedimiento concursal, Indecopi no tiene un conflicto de interés con el administrado. Por tanto, en los procesos contencioso-administrativos en los que se cuestionen los actos administrativos emitidos por Indecopi como parte de su labor en un procedimiento concursal, parecería no configurarse uno de sus principales fundamentos, esto es, el derecho a la tutela jurisdiccional efectiva. Ello nos podría permitir repensar si esta figura debería ser aplicada sin distinciones en todas las estructuras administrativas, que tienen matices y formulaciones diversas, entre ellas, la estructura concursal.

- $\quad$ En el estado de las cosas, algunas acciones concretas como el enfoque de colaboración interinstitucional y/o la creación de juzgados especializados podrían mejorar la interacción entre Indecopi y el Poder Judicial y, a su vez, permitir mejorar la eficacia y eficiencia

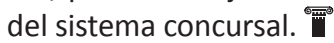

\section{REFERENCIAS}

Comisión de las Naciones Unidas para el Derecho Mercantil Internacional. (2006). Guía legis/ativa sobre el Régimen de Insolvencia. Nueva York, Estados Unidos: Naciones Unidas.

Del Águila, P. (2003). "Poniendo los puntos sobre las íes: objetivos, principios y líneas matrices del sistema concursal”. En: Foro Jurídico (2), p. 64.

Echeandía, L. (2001). “Odisea concursal y crisis empresarial”. En: lus Et Veritas (20), p. 195.

Espinoza, J y Atoche, P. (ed.). (2011). Ley General del Sistema Concursal, Un análisis exegético. Lima, Perú: Rhodas.

Ezcurra, H. (2002). Derecho Concursal: estudios previos y posteriores a la nueva Ley Concursal. Análisis económico del Derecho. Lima, Perú: Palestra editores.

Ezcurra, H. (2016). "La Muerte del Sistema Concursal". En: Revista de la Competencia y la Propiedad Intelectual (12), p. 157.

Gonzáles, J. (1985). Derecho Procesal Administrativo Hispanoamericano. Bogotá, Colombia: Temis.

14 Para mayor información consultar: http://latinlawyer.com/article/1147517/international-insolvency-group-appoints-firstlatin-american-judges. 
Gonzáles, J. (tercera edición). (2001). El derecho a la tutela jurisdiccional. Madrid, España: Civitas.

Instituto Nacional de Defensa de la Competencia y de la Protección de la Propiedad Intelectual. (2013). Análisis de las funciones del Indecopi a la luz de las decisiones de sus órganos resolutivos: Colección por el vigésimo aniversario del Indecopi. Lima, Perú: Indecopi.

Ledesma, M. (2009). “Acceso a la jurisdicción contencioso administrativa". En: Revista Oficial del Poder Judicial (5).

Osvaldo, L. (1992). Introducción al estudio del Derecho Concursal. Antecedentes históricos y Derecho Comparado. Buenos Aires, Argentina: Ediciones Depalma, pp. 141-150.

Priori, G. (cuarta edición). (2009). Comentarios a la Ley del Proceso Contencioso Administrativo. Lima, Perú: ARA Editores.

\section{LEGISLACIÓN, JURISPRUDENCIA Y OTROS DOCU- MENTOS LEGALES}

Comisión Permanente del Congreso de la República. (2002). Ley General del Sistema Concursal. Ley 27809.
Convenio Marco de Cooperación Interinstitucional entre el Poder Judicial de la República del Perú y el Instituto Nacional de Defensa de la Competencia y de la Protección de la Propiedad Intelectual. (31 de octubre de 2014).

Constitución Política del Perú. (1993). Artículo 139 (Título 4).

Corte Suprema de Justicia. (2005). Oficio Circular 007-2005-SP-CS-PJ.

Decreto legislativo 807. (1996). Facultades, normas y organización del INDECOPI.

Proyecto de Ley 2579-2001-CR. (2001).

Texto Único Ordenado de la Ley Orgánica del Poder Judicial. (1993). Artículo 4 (Sección primera).

Tribunal de Defensa de la Competencia y la Propiedad Intelectual. (1997). Precedente de Observancia Obligatoria contenido en la Resolución 079-97-TDC.

Tribunal de Defensa de la Competencia y la Propiedad Intelectual. (2006). Resolución 949-2006/ TDC-INDECOPI contenida en el expediente 882004/CCO-ODI-ESN-03-09. 